Florida International University FIU Digital Commons

4-13-2004

\title{
Predictors of client retention in alternative to prison substance abuse programs
}

Jolae Brocato

Florida International University

DOI: $10.25148 /$ etd.FI14051844

Follow this and additional works at: https://digitalcommons.fiu.edu/etd

Part of the Social Welfare Commons

\section{Recommended Citation}

Brocato, Jolae, "Predictors of client retention in alternative to prison substance abuse programs" (2004). FIU Electronic Theses and Dissertations. 1887.

https://digitalcommons.fiu.edu/etd/1887

This work is brought to you for free and open access by the University Graduate School at FIU Digital Commons. It has been accepted for inclusion in FIU Electronic Theses and Dissertations by an authorized administrator of FIU Digital Commons. For more information, please contact dcc@fiu.edu. 


\section{FLORIDA INTERNATIONAL UNIVERSITY}

Miami, Florida

\section{PREDICTORS OF CLIENT RETENTION IN ALTERNATIVE TO PRISON SUBSTANCE ABUSE PROGRAMS}

A dissertation submitted in partial fulfillment

of the requirements for the degree of

DOCTOR OF PHILOSOPHY

in

SOCIAL WELFARE

by

Jolae Brocato

2004 
To: Dean Ronald M. Berkman

College of Health and Urban Affairs

This dissertation, written by Jolae Brocato, and entitled Predictors of Client Retention in Alternative to Prison Substance Abuse Programs, having been approved in respect to style and intellectual content, is referred to you for judgment.

We have read this dissertation and recommend that it be approved.

Andres Gil

Mark Macgowan

Linda Sobell

Eric F. Wagner, Major Professor

Date of Defense: April 13, 2004

The dissertation of Jolae Brocato is approved.

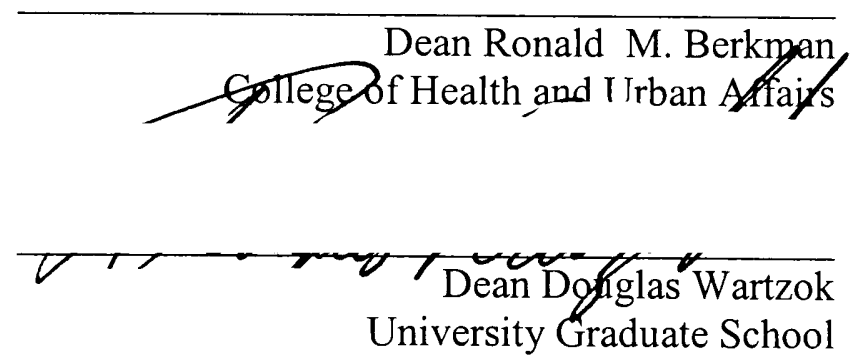

Florida International University, 2004 


\section{DEDICATION}

I would like to dedicate this dissertation to my mother and my daughter who inspired me to realize this effort, and the staff and clients of Spectrum Programs who gave freely of their time and helped me to complete this work. 


\section{ACKNOWLEDGMENTS}

I want to thank my committee members Dr. Andres Gil, Dr. Mark Macgowan, and Dr. Linda Sobell who have influenced my thinking on this topic and challenged me to examine these questions in ways that contribute to the fund of social work knowledge. I particularly want to thank Dr. Eric Wagner for his respect, guidance, patience, and mentoring of my academic pursuits. He has exemplified a passion for research and teaching and has generously provided me with opportunities for intellectual and professional growth. He has given freely of his time and knowledge throughout the entire doctoral program.

Special thanks to Maureen Bethea for her unwavering support and encouragement in life, and throughout this process. I am grateful for her time, and effort in helping me to produce this paper. I would also like to thank Andres Gil, Linda Sobell, William Zywiak, Adam Horvath, and William Miller for sharing their measurement tools and encouragement for this work. 
ABSTRACT OF THE DISSERTATION

PREDICTORS OF CLIENT RETENTION IN ALTERNATIVE TO PRISON

SUBSTANCE ABUSE PROGRAMS

by

Jolae Brocato

Florida International University, 2004

Miami, Florida

Professor Eric F. Wagner, Major Professor

Increased treatment retention among substance abusing individuals has been associated with reduced drug use, fewer arrests, and decreased unemployment, as well as a reduction in health risk behaviors. This longitudinal study examined the predictors of client retention for alternative to prison substance abuse treatment programs through assessing the roles of motivational factors and the client-worker relationship. The sample was comprised of 141 male felony offenders who were legally mandated to community based long-term residential drug treatment programs.

The primary measures used in the study were the consecutive days a participant remained in treatment, Stages of Change Readiness Model and Treatment Eagerness Scale (SOCRATES), the Working Alliance Inventory (WAI), and The Readiness Ruler. Hierarchical multiple regression analysis was conducted for four hypotheses (a) participants who are more motivated to change at the time of entry will remain in treatment longer, (b) participants who have a strong therapeutic alliance will remain in treatment a greater number of consecutive days than participants who have weaker therapeutic alliance, (c) motivation to change, as measured at treatment entry, will be 
positively related to therapeutic alliance, (d) during the course of treatment variation in motivation to change will be predicted by the therapeutic alliance.

Results support the following conclusions: Among clients in alternative-to prison programs the number of days in treatment is positively related to their motivation to change. The therapeutic alliance is not a predictor of the number of days in treatment. Motivation to change, particularly recognition of a drug problem, is positively related to the therapeutic alliance. Changes in motivation to change in response to treatment are positively related to the therapeutic alliance among clients in an alternative to prison substance abuse treatment programs. These results carry forward prior research and have implications for social work practice, research, and social welfare policy. 
I. INTRODUCTION

II. LITERATURE REVIEW

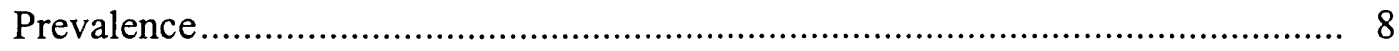

Substance Use, Abuse, Dependence ........................................................... 8

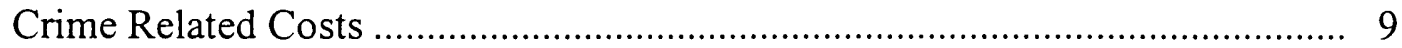

Drug Users and The Criminal Justice System ……....................................... 11

Community Justice Treatment Initiatives ..................................................... 12

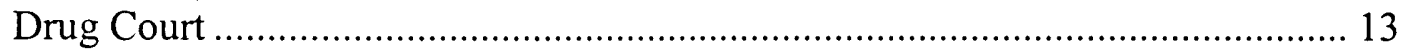

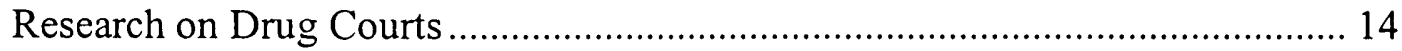

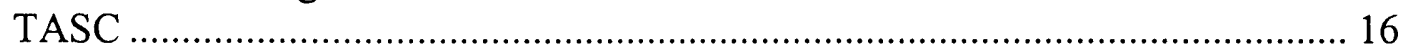

Legally Mandated Treatment ............................................................................. 17

Research on Compelled/Mandated/Coerced Treatment .................................... 18

Treatment Readiness/Treatment Seeking .......................................................... 20

Caveat: Is Treatment or Research Ever Voluntary? ......................................... 21

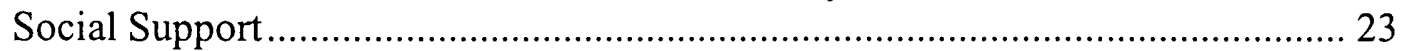

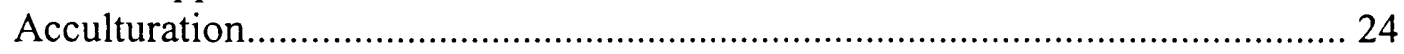

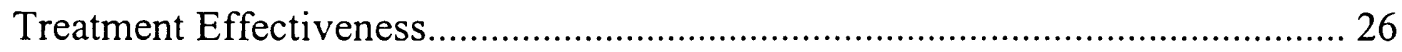

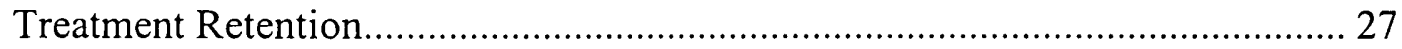

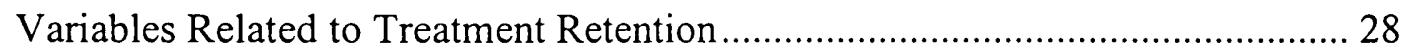

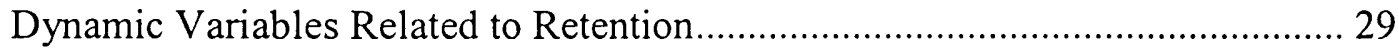

III. METHODOLOGY

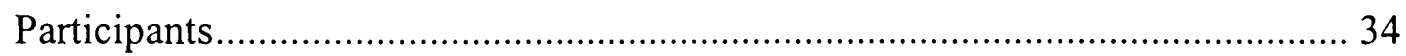

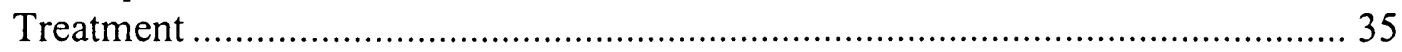

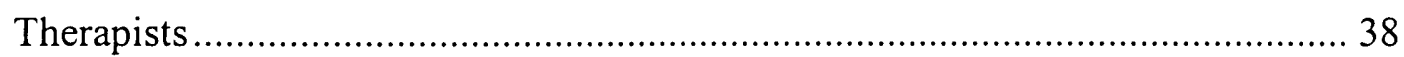

Stages of Change Readiness Model and Treatment Eagerness Scale .................. 38

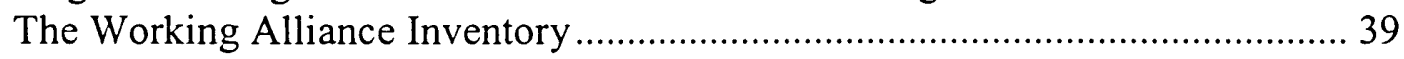

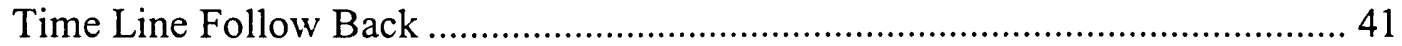

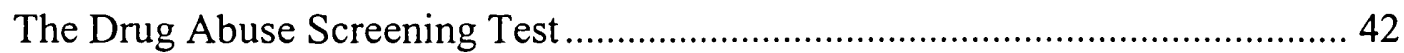

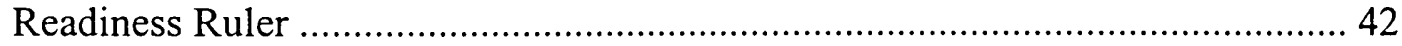

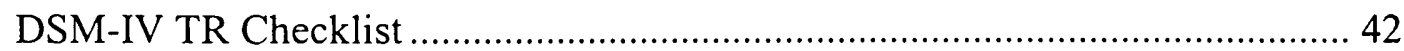

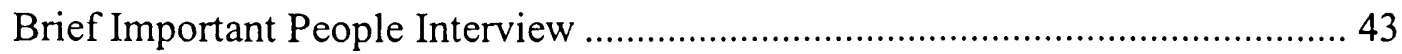

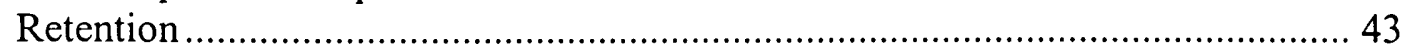

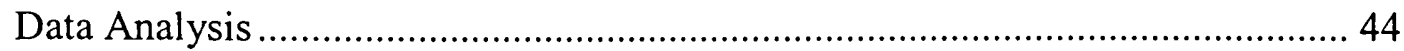

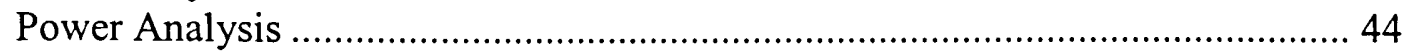

IV. RESULTS

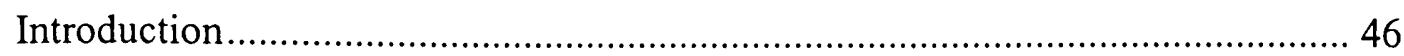

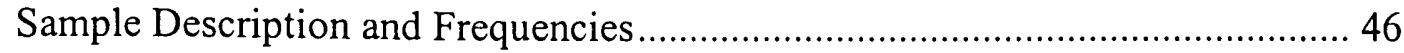


IV. RESULTS (continued)

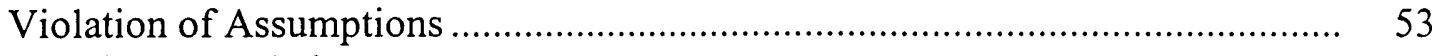

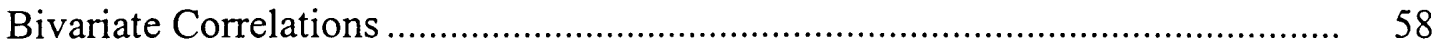

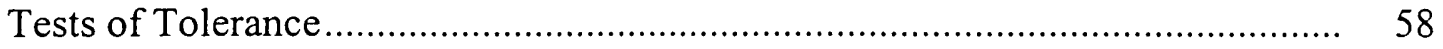

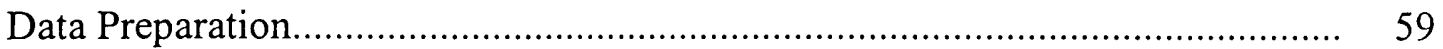

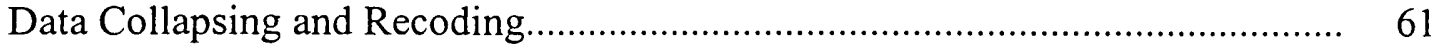

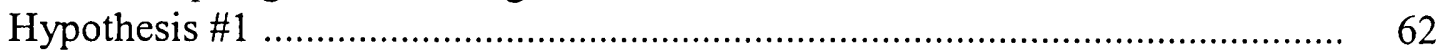

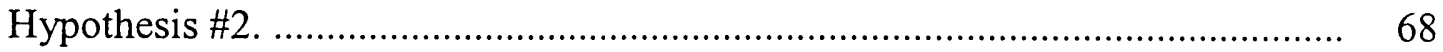

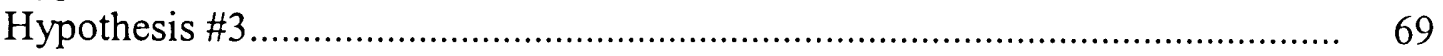

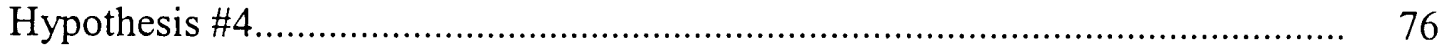

V. DISCUSSION

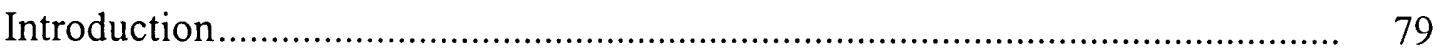

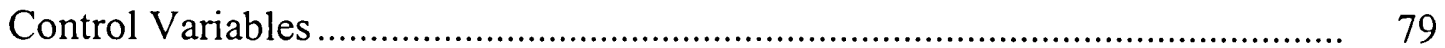

Motivation to Change as a Predictor of Retention.............................................. 82

The Therapeutic Alliance as a Predictor of Retention ...................................... 85

Motivation to Change as A Predictor of the Therapeutic Alliance..................... 88

The Therapeutic Alliance Increases Motivation to Change................................. 93

Limitations of the Study.............................................................................. 96

Suggestions for Further Research ............................................................ 98

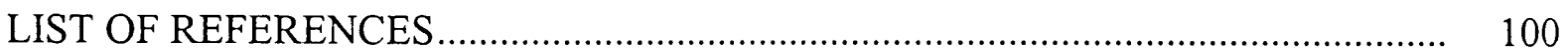

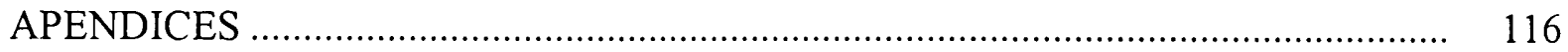

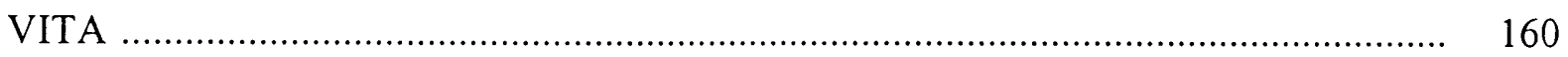




\section{LIST OF TABLES}

TABLE

PAGE

1. Client Demographics By Location and Average Days Retained 36

2. Characteristics of the Sample by Retention Status 48

3. Legal and Treatment Characteristics 50

4. Acculturation 51

5. Brief IPA Time 1 55

6. Brief IPA Time 2 56

7. Measures 57

8. Acculturation Factors. 58

9. Collinearity Statistics 61

10. Days regressed on SOCRATES 65

11. Days regressed on SOCRATES Subscales 66

12. WAI Total Score regressed on SOCRATES Subscales 69

13. WAI Bond Score regressed on SOCRATES Subscales 70

14. WAI Total Score regressed on Readiness Ruler. .71

15. WAI Bond Score regressed on Readiness Ruler. .72

16. WAI Task Score regressed on Readiness Ruler 73

17. WAI Goal Score regressed on Readiness Ruler 73

18. Time 2 SOCRATES regressed on Time 1 SOCRATES WAI Subscale Scores... 75

19. Collinearity Statistics

20.Collinearity Statistics.

21.Collinearity Statistics. 